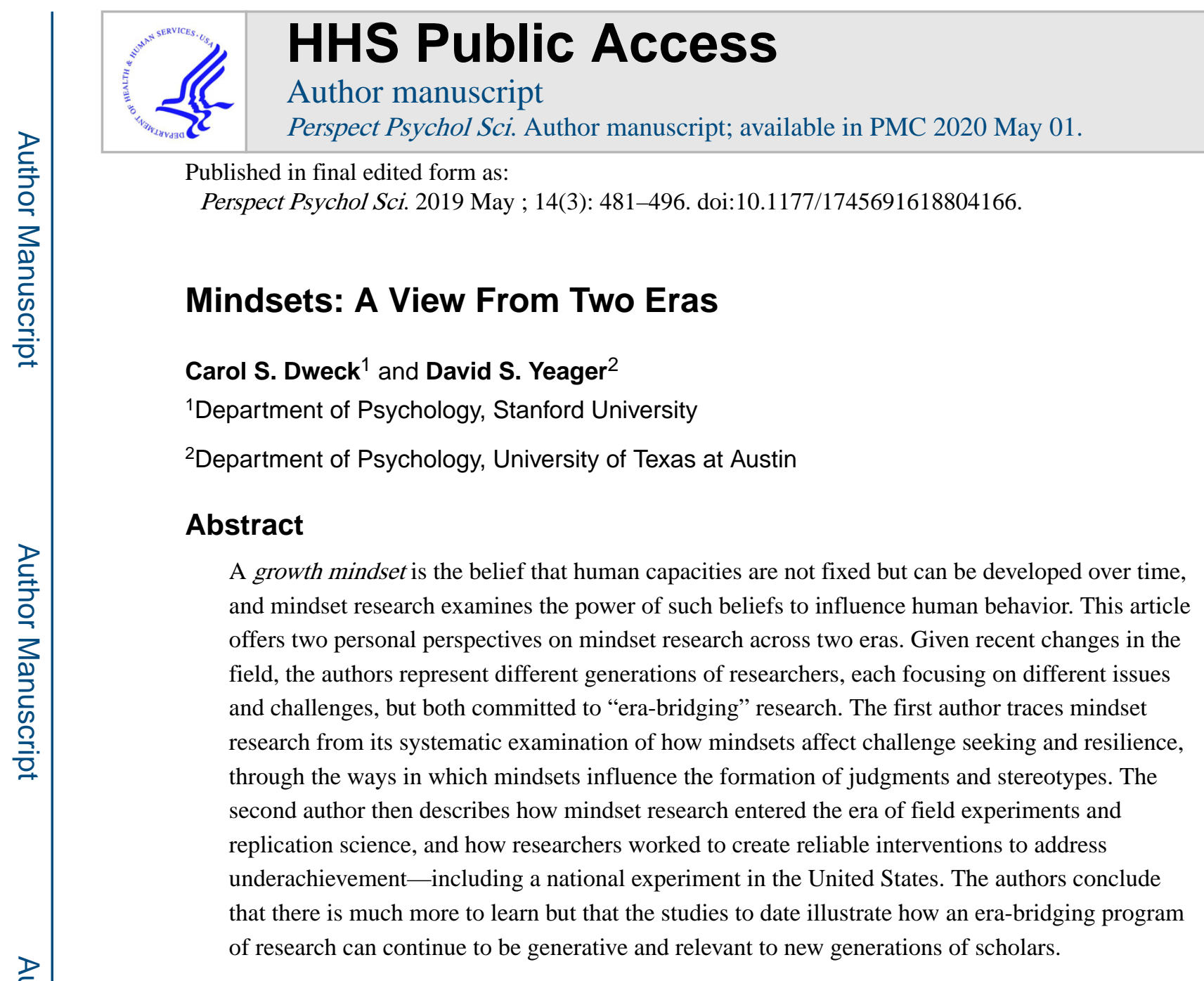

\title{
Keywords
}

biography; autobiography; history

\begin{abstract}
The first author (Carol Dweck) was invited to write a personal retrospective on mindset research as part of a series in which mature scientists reflect on their careers and offer sage advice to younger scholars. But as she pondered this, she thought, "Maybe the young scholars are not all that eager to hear from us. We came of age in a different era, things have changed, and maybe our advice doesn't seem so relevant." With this in mind, she invited her younger colleague David Yeager to join forces with her. For the past 12 years, David has taken mindset research in new exciting directions and into the era of field research and replication science. With his expertise in research methods, statistics, and intervention science, as well as his reach across areas of psychology, he has helped make mindset research into an interdisciplinary, international, and generalizable effort. The first author is
\end{abstract}

\footnotetext{
Corresponding Authors: Carol S. Dweck, Department of Psychology, Jordan Hall, Stanford University, Stanford, CA 94035, dweck@stanford.edu, David S. Yeager, Department of Psychology, 108 E. Dean Keeton Stop A8000, Austin, TX, 78712-1043, dyeager@utexas.edu.

Declaration of Conflicting Interests

The author(s) declared that there were no conflicts of interest with respect to the authorship or the publication of this article.

Action Editor

June Gruber served as action editor and interim editor-in-chief for this article.
} 
your primary guide for the first half of this article, and David is your primary guide for the second half. 1

In his sections, David addresses a challenge that he faced-one that many young scholars entering the field today may face as they figure out what to make of the foundational findings from the era that preceded them. With an increased and important focus on replication, and with advances in methodology, scholars entering the field want to know: What can I trust? And, when previous findings prove to be replicable, what can I contribute to a program of research that seems well-established?

The goal here is to show how we and our colleagues have tried to carry out research that takes the hard-fought insights from a past era, brings them into conversation with the methods of today, and generates a new program of research that belongs to the new erawhat we call era-bridging research.

\section{Introduction to the Research}

People can believe that a particular attribute, such as intelligence or personality, is simply fixed. Or they can believe that it can be shaped and developed. This article tells the story, thus far, of a research program on people's beliefs about the nature of human attributes and the consequences of the differing beliefs.

As with any research program, there have been highs and lows, triumphs and setbacks, but two things always saw me through any setbacks. First, I (C. Dweck) have always had a tremendous research group. My students and postdocs have made my career a great joy. We always believed there was nothing we could not solve with enough thought and discussionand, of course, research. Even in moments of discouragement or anxiety, we had great faith in each other and our ability to problem-solve together.

The second thing is my love for my area of research. I am fascinated by how motivation affects people's success, independent of their starting ability. And I am fascinated by the beliefs that underlie this motivation. It is my deep conviction that if you love your topic, have endless curiosity about it, and believe in its importance, it will inevitably be a powerfully rewarding journey. You will always leave something others can build on.

\section{Beliefs about human malleability}

The belief that human attributes can be developed has a long history, with a turning point in the Renaissance. The Renaissance was not just a period in which the arts and sciences flourished. It was, perhaps more importantly, a time when a new conception of what makes us human came into prominence. Giovanni Pico della Mirandola, a key thinker of the age, argued that we humans are the only species with the ability to transform ourselves (Pico Della Mirandola, 1486/2012). In fact, he argued that the very dignity of humans lies precisely in their potential to make themselves into what they aspire to be. This view stood in stark contrast to historical notions of fixed endowments and predetermined positions in

\footnotetext{
1.Specifically, Carol Dweck is the first-person ("I") voice in Sections 1, 2, 3, and 5, and David Yeager is the first-person ("I") voice in Sections 4 and 6.
} 
the hierarchy of merit. Although our research does not speak directly to the accuracy of different views, it does speak to the impact of believing in human malleability (for a perspective on the actual malleability of human intelligence, see, e.g., Sauce \& Matzel, 2018).

\section{Overview of the article}

What is the impact of holding a fixed mindset about intelligence (the belief that intelligence cannot be developed) versus a growth mindset about intelligence (the belief that intelligence can be developed, for example, through personal effort, good learning strategies, and lots of mentoring and support from others)? In this article, David Yeager and I trace mindsets from a fledgling idea to a theory of challenge-seeking and resilience, and then into this new scientific era: to the development of replicable growth-mindset interventions aimed at enhancing motivation and well-being on a larger scale. We describe the developments in some detail so that the reader can understand how the research program took root and then sprouted in new directions.

It is important to note, however, that as much as we have learned, our research to date is just a foundation for what is to come. This may sound strange to say after decades of research, but we still know far too little about how best to transmit a growth mindset to individuals, how contexts determine whether students take up and apply a new mindset, or how to help embed a growth mindset in the cultures of schools and organizations. Research into these issues is critical because we have learned that it is too easy for people to implement a growth mindset poorly. We are also beginning to understand how mindsets and kindred concepts fit into larger theories of motivation, personality, and development, and this too is an exciting new direction.

\section{Mindset's Genealogy: Learned Helplessness and Attribution Theory}

Research on mindsets has an interesting lineage. I entered graduate school in the late 1960s, as behaviorism was losing its supremacy in psychology and the cognitive revolution was dawning. During the long behaviorist era, talk of cognitive processes was banned and even mocked. Indeed, when the great learning theorist Edward Tolman proposed that cognitions resulted from and guided the learning process, he was taunted for leaving his rats "buried in thought" (Guthrie, 1935, p. 172). Yet, people (and animals), as they navigate and learn about their environments, must inevitably develop beliefs about how the world works. How can these beliefs not have important implications for what they do and how they do it?

As psychology entered the cognitive revolution, animal learning theory itself (the field I was in at the time) took on a more cognitive cast. For example, work on learned helplessness in animals (Seligman \& Maier, 1967) suggested that organisms formed beliefs from their experiences and that these beliefs could then play a key role in their motivation. In this case, animals exposed to uncontrollable shocks later made little effort to prevent or terminate shocks, even when the shocks became controllable.

I was intrigued by these findings and, just a few years later, I set out to integrate the work on learned helplessness in animals with the emerging work on attribution theory in humans 
(e.g., Weiner \& Kukla, 1970). Attribution theory proposed that people try to find explanations for what happens to them and that these explanations then shape their reactions. For example, students who explain their failure as being due to a lack of ability may well react differently to a failure than students who blame their effort, something that is typically more under their control (Weiner \& Kukla, 1970).

To achieve this integration, I, with Dick Reppucci (Dweck \& Reppucci, 1973) and Carol Diener (Diener \& Dweck, 1978), confirmed that children's attributions could in fact predict a "helpless" or "mastery-oriented" response to setbacks, even in children with equal ability on a task. Depending on how they interpreted a failure, some children simply wilted, whereas others showed a remarkable tendency to relish the challenge. But I still struggled to understand: Why would students of roughly equal ability show such different attributions and reactions?

To address this question, Elaine Elliott and I (Elliott \& Dweck, 1988; see also Nicholls, 1984) helped build the foundation of achievement goal theory by showing that student's achievement goals - performance goals (the goal of validating or proving your ability) versus learning goals (the goal of developing your ability) — could set the stage for the different reactions to setbacks (see also Grant \& Dweck, 2003). But a key question still remained: Among students with roughly equal ability, why might some care more about proving their ability and others more about improving it? Along came Mary Bandura to help answer this question, and, with this, mindset research was born.

\section{The First Era of Mindset Research}

Mary Bandura and I were exploring topics for her PhD thesis (Bandura, 1983) when we suddenly realized that the "ability" that people wish to prove had a different feel to it than the "ability" that people wish to improve. A strong wish to prove the adequacy of one's ability makes that ability seem like a deep-seated, fixed attribute of the self, whereas a strong desire to improve one's ability makes it seem like a more dynamic quality that can be developed. Immediately, I shifted the focus of my research to these different views of ability, which we called implicit theories of intelligence. We called them theories because they were potentially falsifiable ideas about what intelligence is and how it might work. We called them implicit because we believed that people were often unaware of them. (The two implicit theories were originally called entity and incremental theories, but I later changed the names to the more user-friendly terms of fixed and growth mindsets; Dweck, 2006).

It took a lot of hard work to hone the idea and to develop ways to reliably assess and manipulate these theories or mindsets, but once we did we were off and running. We were moving further toward the goal of understanding the psychology behind challenge seeking and resilience — why some people run from difficulty, while others run to it — and perhaps toward the goal of understanding why some people fulfill their potential and others do not.

\section{Mindsets as the core of meaning systems}

Earlier, I talked about how people form beliefs on the basis of their experiences and how these beliefs can guide their motivation and behavior. Now, some beliefs are not isolated 
ideas, but rather can serve an organizing function, bringing together goals, beliefs, and behaviors into what might be called a meaning system (Hong, Chiu, Dweck, Lin, \& Wan, 1999; Molden \& Dweck, 2006). My students and I proposed that mindsets create meaning systems. Indeed, we proposed that mindsets might organize virtually all of the variables we had previously studied (including goals, attributions, and helplessness) into one meaning system. To these variables, we added the concept of effort beliefs — believing that effort is a positive thing that helps grow your ability, as opposed to a negative thing that demonstrates deficient ability (for research on the relation between mindsets and effort beliefs, see Leggett, 1986; Miele \& Molden, 2010; Miele, Son, \& Metcalfe, 2013).

That is, we proposed that when people are in a fixed mindset (compared with a growth mindset), all these variables can take on different importance or meaning. Specifically, when people view ability as fixed, then validating their ability (by pursuing performance goals or by avoiding challenges) can take on more importance, high effort may more readily be seen as indicating low ability, and setbacks are more easily attributed to low ability. When this happens, persistence can be curtailed. In contrast, when people view ability as something that can be improved, then developing that ability (by taking on challenging learning goals) can become more important, effort may be seen as a tool in this process, and setbacks can more readily be seen as information about the learning process. When this happens, persistence can be sustained.

The research that followed carefully examined these meaning systems, especially the implications of the mindsets for students' seeking of challenging learning tasks and for persistence in the face of setbacks. In our first article on mindset theory, Ellen Leggett and I (Dweck \& Leggett, 1988) spelled out the theory's predictions and its proposed mechanisms —and also provided an initial test of the challenge-seeking hypothesis.

Later, with Ying-Yi Hong and C. Y. Chiu (Hong et al., 1999), we took the challenge-seeking hypothesis into the real world, looking at the desire for challenging learning goals in students entering the University of Hong Kong. At this elite university, all courses were conducted in English and all materials and exams were in English, but not all students were proficient in English. For this reason, we asked the students how interested they would be in taking a high-quality remedial English course if it were offered. Students who endorsed a fixed mindset were not very enthusiastic about taking such a course, even when they were low in English proficiency. However, students who endorsed a growth mindset and were low in English proficiency were substantially more enthusiastic about taking the course. They seemed willing to expose a deficiency for the sake of correcting it. These findings were conceptually replicated in an experimental study in which students' mindsets were temporarily induced, demonstrating the causal effects of the mindsets (Hong et al., 1999, Study 3).

Still later, with David Nussbaum, we conducted a series of experiments demonstrating the causal role of mindsets in students' desire to undertake further learning after a clear failure, as opposed to taking defensive measures that would shore up their sense of their ability but would in no way improve their actual ability (Nussbaum \& Dweck, 2008). Looking inside the brain, Moser, Schroder, Heeter, Moran, and Lee (2011) then brought to light these 
processes at the neural level, demonstrating again the enhanced focus on learning after errors that accompanies a growth mindset about intelligence (see also Mangels, Butterfield, Lamb, Good, \& Dweck, 2006).

Thus, research supported the idea that mindsets can play a role in the desire for challenging learning and in the persistence of that desire even in the face of obstacles or failures. Larger studies also tested the overall meaning-system framework. Robins and Pals (2002), in a correlational study, followed 363 students at the University of California at Berkeley across 3 years of college, along the way assessing reports of their mindsets, goals, attributions for academic outcomes, and helpless responses to setbacks. They found direct paths from mindsets to all of these other variables, as well as indirect paths from mindset to helpless responses versus mastery-oriented responses through these variables (and through affective responses).

In a later correlational study, Blackwell, Trzesniewski, and Dweck (2007, Study 1) followed 373 students across the difficult transition to junior high school (7th grade) for a period of 2 years (7th and 8th grades), measuring many of the same variables assessed by Robins and Pals (2002) and adding beliefs about effort. Our model showed clear paths from mindsets to goals, effort beliefs, and attributions and on to reports of mastery-oriented versus helpless responses in the face of setbacks. In this study, the mastery-oriented responses then went on to predict changes in math grades over the 2-year period of this challenging transition.

Studies have gone on to replicate these basic meaning-system associations and to find correlations between mindsets and students' grades. Perhaps most compelling are data from a recent nationally representative sample of more than 14,000 9th-grade students (Yeager et al., 2018; see also data from more than 100,000 students in the state of California in West, Buckley, Krachman, \& Bookman, 2018). Using data from the nationally representative sample, we replicated the meaning-system predictions and found that the average correlation between fixed mindset and GPA for 9th-grade students in the United States is -.22 (see Figure 1).

The findings from correlational and experimental research showing that a growth mindset can predict and promote more challenge seeking, resilience, and positive outcomes do not mean that a growth mindset is always positive. Perhaps some personal attributes cannot or should not be changed. Perhaps a growth mindset can be used for negative ends (getting better at an ability that is used to inflict harm), and perhaps it is sometimes appropriate or wise to give up (persistence without progress should always be questioned). Our findings simply suggest that a growth mindset can form the core of a larger meaning system that can, under favorable conditions, help people engage in thoughts and actions that lead them closer to their goals.

\section{Where do these mindsets come from?}

I was deeply curious to know how these meaning systems might be formed. Where do they come from? As children try to make sense of the world of intelligence, what experiences might they learn from? My students and I decided to start our search for the antecedents of mindsets by examining what children learn from praise for their successes. Claudia Mueller 
and I (Mueller \& Dweck, 1998) conducted six studies on the effects of praise for success in late grade-school children. Across the studies, we demonstrated that after a success, praise for intelligence (person praise), compared with praise for effort (process praise) or praise for outcome, was more likely to induce a fixed mindset, along with its old friends: performance goals, low-ability attributions for failure, and impaired performance (helpless reactions) following failure. ${ }^{2}$

Kamins and Dweck (1999), working with younger children, examined the impact of person praise and criticism compared with process praise and criticism, this time including strategy feedback as a form of process feedback. We again found that person feedback (vs. process feedback) led to a greater belief in stable traits and greater helplessness in the face of criticism or failure (for more research on the effects of person praise, see Cimpian, Arce, Markman, \& Dweck, 2007; Zhao, Heyman, Chen, \& Lee, 2017). Later, Gunderson and colleagues (2013) and Pomerantz and Kempner (2013) took this phenomenon into the real world and showed a relationship between parents' process or person praise and children's subsequent mindsets. The work on praise was our first foray into potential antecedents of mindsets and an initial window into how children derive meanings from their experiences.

Then, a few years ago, my student Kyla Haimovitz began to study how parents might transmit mindsets to their children through their reactions to the children's failures. One day, after analyzing data from a number of her studies, she came to my office and announced that she was finding little if any correlation between parents' and children's mindsets. I was surprised. I might have even gulped. So I said to her, "Are you sure?" And when she said yes, I said, 'I'm all in. Let's figure this out." Her research found that it was parents' beliefs about failure and their reactions to children's failures that consistently predicted their children's mindsets (Haimovitz \& Dweck, 2016; for a discussion of how overt cues such as adults' praise or reactions to failure might be more visible to children than the adults' actual mindsets, see Haimovitz \& Dweck, 2017). The question of what other cues from the environment children may use to construct their mindsets is an exciting area for future research.

\section{Social judgments: Traits and stereotypes}

It is also critical for people to develop theories about their social world, and so we began to ask: Can people look at others through the lens of a fixed mindset or a growth mindset? If so, how does that affect how they view and interact with them? For a long time, my students and I struggled with these questions, how to formulate them, and how to wrestle them into testable form. Working with Cynthia Erdley, C. Y. Chiu, Ying-Yi Hong, Sheri Levy, Steve Stroessner, Jason Plaks, and Daniel Molden, we began to show that mindsets could play a distinct role in how people judge others, both individuals and groups (for reviews, see Dweck, Chiu, \& Hong, 1995; Levy, Plaks, Hong, Chiu, \& Dweck, 2001; see also Plaks, 2017). Because person judgments and group stereotypes cut across human attributes, in this research we assessed a more domain-general mindset, rather than focusing on just intelligence. We used such items as "everyone is a certain kind of person, and there is not

\footnotetext{
2.Readers interested in exploring or reanalyzing the original raw data from Studies 1 and 2 in Mueller and Dweck (1998) can find it here: http://osf.io/kgfhu/
} 
much that can be done to really change that" or "the kind of person someone is is something very basic about them and it can't be changed very much" versus "everyone, no matter who they are, can significantly change their basic characteristics."

If people believe in fixed traits, will they infer traits more quickly and invest them with more power? First, we learned that those with a fixed view of human attributes did in fact more readily infer traits from behavior and invest traits with more predictive power (Chiu, Hong, \& Dweck, 1997; Erdley \& Dweck, 1993). For example, those with a fixed mindset took traits or even one trait-relevant behavior and made stronger forecasts about what a person would do in the future than did those who favored more of a growth mindset (i.e., they showed the fundamental attribution error more strongly; Chiu et al., 1997, Studies 1 and 2). This tendency was found in two distinct cultures (the United States and Hong Kong; Chiu et al., 1997, Study 4); moreover, an experiment in which mindsets were manipulated suggested a causal role for the mindsets in the process (Chiu et al., Study 5; for more about mindsets and the mechanisms underlying mindset differences in trait inferences, see McConnell, 2001; Molden, Plaks, \& Dweck, 2006; Plaks, 2017).

If the differing kinds of judgments that arise from mindsets apply to groups too, it could suggest a role for mindsets in stereotyping. Five studies by Levy, Stroessner, and Dweck (1998) showed the ability of mindsets to predict differences in stereotyping of groups. People endorsing more of a fixed mindset made stronger stereotypical judgments of ethnic and occupational groups and formed more extreme trait judgments of new groups. Further, mindsets predicted stereotype endorsement above and beyond other relevant individual difference variables, and manipulating mindsets suggested their causal role in the stereotyping process (for related findings with children, see Levy \& Dweck, 1999).

We learned that mindsets can play another role in the maintenance of stereotypes-in how people respond to information that conflicts with stereotypes. Four studies by Plaks, Stroessner, Dweck, and Sherman (2001) showed that mindsets predicted altered attention to information that supported or conflicted with stereotypes; a fixed mindset (whether measured or manipulated) was associated with heightened attention to information that was consistent with and supportive of existing stereotypes. Taken together, this research shows that stereotyping can be influenced by beliefs about human nature that on the surface may seem unrelated to stereotypes. Mindsets are beliefs about whether human attributes are fixed or malleable, but they can lead people to invest group labels with greater meaning and, thus, to grasp them more quickly and hold onto them more firmly.

We were also fascinated to find that seemingly prejudiced behavior can grow out of mindsets, even apart from stereotypes or prejudice - that is, even when it is not motivated by stereotyping. In eight studies, Carr, Dweck, and Pauker (2012) examined the impact of believing that prejudice is a relatively fixed human trait as opposed to something that can be improved. For example, participants were asked to agree or disagree with such statements as, "people have a certain amount of prejudice and they can't really change that" versus "no matter who somebody is, they can always become a lot less prejudiced." Quite apart from participants' level of implicit or explicit prejudice, those who believed that prejudice was fixed appeared to be more worried about discovering prejudice in themselves or looking 
prejudiced to others. In line with this, they showed lowered interest in interracial interactions and diversity-related activities and heightened symptoms of anxiety (including physiological symptoms) in an actual interracial interaction. In other words, even people who are low in implicit or explicit prejudice may avoid cross-group interactions if they worry about feeling or appearing prejudiced - that is, about detecting or displaying a negative and unchangeable quality of the self.

This research by Carr et al. (2012) suggests that programs meant to encourage diversity should not just call out prejudice. Instead, these programs also need to contain a message about the malleability of prejudice and suggest how intergroup interactions can help individuals learn more about other groups and become more comfortable interacting with members of different groups. This message may be increasingly important given that many people are inexperienced at cross-race interactions, perhaps in part because of growing levels of neighborhood segregation in the United States (Owens, Reardon, \& Jencks, 2016).

In summary, once we drilled down and carefully laid the foundation for understanding mindsets and their relation to personal motivation, we were able to extend this understanding to a very different set of phenomena: people's judgments of others and their behavior toward them. Thus, mindset research began to illuminate not only the scope of people's own strivings but also the potential scope and nature of their social world.

\section{The Current Era: Interventions and New Domains}

When I (D. Yeager) first encountered the research on growth mindset, in my first year as a graduate student (2006 to 2007), it was thrilling. As someone who had taught middle school English to adolescents from lower income families, the idea that mindsets could help me understand why some students embraced challenges gave me hope for improving education. 3

Nonetheless, if mindsets were just another fixed trait, it would be harder to envision how to use mindset research to improve people's lives. What captured my attention-and ultimately my own program of research-was the evidence, just beginning to emerge at the time, that mindsets could be changed and that doing so could, under some conditions, alter motivation and behavior. Even so, the standards and approaches of my generation of scholars revealed ways in which mindset research could be even stronger. This included replications using larger samples, more efficient and scalable means of intervention delivery, and greater attention to generalizability and social context. It also included connections to new and different problems, such as the causes, prevention, or alleviation of adolescent aggression, depression, and stress. The exciting prospect of effective interventions that grew out of a well-studied theoretical model_-one culmination of the first era of mindset research-led us into a second era of mindset research — an era characterized by intervention studies addressing the question of mindset change using large samples and longitudinal designs, and extensions of mindset research into new domains.

\footnotetext{
3. Note that a condition in the Good et al. (2003) study that manipulated attributions (a documented mediator of mindset effects) was also successful in raising test scores.
} 


\section{Early growth-mindset interventions}

In 2006, when I began conducting mindset research, there were only two published growthmindset interventions (J. M. Aronson, Fried, \& Good, 2002; Good, Aronson, \& Inzlicht, 2003) and one in press (Blackwell et al., 2007). In the late 1990s, Joshua Aronson, then a postdoctoral scholar at Stanford University, wondered whether a fixed mindset might play a role in the Black- White achievement gap. Over the course of several sessions, J. M. Aronson et al. (2002) taught college students a growth mindset-including the memorable metaphor that the brain is like a "muscle" that gets stronger with exercise. Aronson and colleagues also asked participants to use what they learned to write mentoring letters to struggling middle school students. Their letters (meant to help the college students internalize the growth mindset) encouraged the younger students to persevere, reminding them that their brains were growing as they confronted challenging work. Aronson and colleagues found that the African American college students who received the growthmindset intervention went on to earn higher grades than their counterparts in the control groups and to show an increase in their enjoyment and valuing of academic work.

Not long after, Good et al. (2003) and then Blackwell et al. (2007, Study 2) designed and carried out growth- mindset interventions for adolescents, a vulnerable age at which declines in achievement are common and can have important consequences for future life success. These multisession, in-person interventions capitalized on the "brain is like a muscle" metaphor, presenting the idea that the brain forms new or stronger connections with rigorous learning, and targeted students who were academically at risk: 7th-grade students from racial and ethnic minority groups. In these studies, students in the growth-mindset group earned higher achievement test scores (Good et al., 2003) or math grades (Blackwell et al., 2007) than students in the control group. ${ }^{3}$

The initial ventures into growth-mindset interventions set the template for intervention studies to come. The standard approach became, first, to teach scientific information about the brain and its malleability - that the brain is made up of networks of neurons and that these networks become "stronger" and more efficient when people learn new and challenging material. The interventions also find creative ways to invite students to reflect on and "own" this idea as they try to apply it to their own lives, such as J. M. Aronson's method of writing letters to future struggling students who might benefit from having a growth mindset—a technique called saying-is-believing (see E. Aronson, 1999; Walton, 2014; Wilson, 2011).

\section{Taking the growth-mindset intervention online-and to scale}

Growth-mindset interventions showed promise for changing students' academic performance when delivered face-to-face. But it was apparent to us that the time and expense of training facilitators for these face- to-face workshops sharply limited the potential for scaling and replication. For this reason, around 8 years ago, Dave Paunesku, Carissa Romero, and I set out to discover whether a growth mindset intervention could be delivered online. This was a turning point because it increased the ease with which we could replicate the intervention in more, and more diverse, contexts. This work would not have 
been possible even a few years earlier, because many schools did not have devices with Internet access for entire cohorts of students.

Initially, we did not know whether it would be possible to shift students' mindsets through a short online experience, let alone improve their grades months later. After all, adolescents are notoriously resistant to adults' efforts to change them (see Yeager, Dahl, \& Dweck, 2018). Of course, we did not expect effects for online interventions to be nearly as large as the ones found for in-person workshops, but we thought it would be amazing (a) if we could change mindsets with a short, direct-to-student online program and (b) if this resulted in any change in grades across the very different schools, teachers, curricula, and peer groups.

Over the past 8 years, we have conducted randomized trials with tens of thousands of students (Paunesku et al., 2015; Yeager, Walton, et al., 2016), including two preregistered replications (Yeager, Hanselman, et al., 2018; Yeager, Romero, et al., 2016). The data show that online interventions can change mindsets and academic outcomes under certain conditions. Effects on academic outcomes are of course modest, and they typically appear for students with higher levels of risk for academic underperformance: high school students who had lower grades before the intervention, especially if they were attending medium-tolow-achieving schools (Bettinger, Ludvigsen, Rege, Solli, \& Yeager, 2018; Paunesku et al., 2015; Yeager, Hanselman, et al., 2018; Yeager, Romero, et al., 2016) and college students who belonged to underrepresented or stereotyped groups (students of color or firstgeneration college students; Broda et al., 2018; Yeager, Walton, et al., 2016). Therefore, growth-mindset interventions may be useful in addressing a portion of inequalities in education at scale and at an extremely modest cost.

But what about higher achieving students? Are growth-mindset interventions of any value for them? We learned that students who already have high grades also change their mindsets in response to our intervention, but they show benefits in terms of other outcomes, such as a willingness to take on challenges (Yeager, Romero, et al., 2016) or take advanced math up to a year later (Yeager, Hanselman, et al., 2018). Such challenge-seeking behaviors might push them to develop higher level skills, which could benefit them in terms of lifelong health and work outcomes (Carroll, Muller, Grodsky, \& Warren, 2017).

\section{Lessons from the era of interventions and replications}

So far, there have been several important lessons from our efforts to bring mindset research into the current era of psychological science. First, it has become clear that effect sizes coming from field studies conducted in heterogenous samples with real-world, longitudinal outcomes should be evaluated differently from effect sizes coming from laboratory studies. In the previous era of mostly laboratory experiments, it might have been useful to compare effect sizes with theoretical benchmarks such Jacob Cohen's (1988) cut points for small, medium, or large effects. But as mindset experiments have come to look more like randomized trials, it has become important to employ the more appropriate benchmarks for effect sizes in educational evaluation studies (e.g., Hill, Bloom, Black, \& Lipsey, 2008).

Most interventions in education-including those that test new curricula, teacher-training models, or school redesigns_-have found no effects on student outcomes, often despite 
considerable cost (see Boulay et al., 2018). In fact, according to government databases of rigorously evaluated programs, such as the What Works Clearinghouse (https://ies.ed.gov/ ncee/wwc/) or the Investing in Innovation Fund (Boulay et al., 2018), some of the best-inclass (i.e., successful) studies with adolescents have effects on lower achieving students' GPA of around .06 grade points (Somers et al., 2010) and increase the number of students on track to graduate by 3 to 8 percentage points (Weiss et al., 2017). The largest effects in the literature for large-sample, randomized controlled experiments with adolescents are roughly .20 SD (see, e.g., Cheung \& Slavin, 2016; Nye, Hedges, \& Konstantopoulos, 2000; see also Dynarski, 2017). These benchmarks are equal to or smaller than Cohen's cut point for small effects, but they are realistic and meaningful.

It is striking then, that brief, online, direct-to-student growth-mindset interventions have produced effect sizes that are comparable with those of many extensive and costly programs for adolescents that are considered successful. A typical online growth-mindset program has effects on lower achieving students' GPA of around .10 grade points (with double that in certain school contexts), and/or improvements of 4 to 8 percentage points in lower achieving students' rates of being on track for high school or college graduation (Paunesku et al., 2015; Yeager, Hanselman, et al., 2018; Yeager, Romero, et al., 2016; Yeager, Walton, et al., 2016). Again, although seemingly small relative to laboratory study benchmarks, or relative to the total amount of variance in the outcome, these are effects on longer term educational outcomes in the real world. If these effects could be seen across the nation, then many thousands more students per year could be helped to finish 9th grade on track for graduation.

A second lesson from the new era of replications and field experiments is that interventions that are easy to deliver (i.e., by taking students to the computer lab to do a survey) are not necessarily easy to develop. As growth-mindset materials have moved from being employed in laboratory experiments with well-understood populations (i.e., undergraduates at one's home university) and into the vastly heterogeneous schools across the nation, it has been important to recognize that these interventions are highly dependent on subtle features of the materials and procedures and on how they are matched to the target population.

For the National Study of Learning Mindsets, Romero, Paunesku, Dweck, and I carried out extensive research and development (R\&D) to craft materials so they were ready for the target population: a nationally representative sample of entering high school students (Yeager, Romero, et al., 2016). This R\&D process involved several years and thousands of pilot participants (Yeager, Romero, et al., 2016; see Table 1). Below, we lay out the broad approach, because our R\&D methods may provide a useful guide for other researchers interested in interventions.

In the National Study of Learning Mindsets, we sought to develop the most effective growth mindset message that we could for beginning 9th graders and one that could be administered in two 25-min sessions. We made sure not only to present interesting information about the brain but also to help students use this information to understand how challenges and setbacks could foster greater learning. We did not simply teach students the idea of the growth mindset; we also included exercises that gave students ownership of the concept and a sense of why it is an important concept. 
Phase 1 of the R\&D evaluated the "base" intervention materials that had been used in previous randomized trials with over 9,000 students from 2010 to 2012, including evaluations with high school students (Paunesku et al., 2015), community college students (unpublished data described in Yeager \& Dweck, 2012), and 4-year college students (Yeager, Walton, et al., 2016). But that did not mean that they were the best we could do for 9th-grade students making the transition to high school.

Therefore, in Phase 2, we immersed ourselves in the psychological world of 9th-grade students: When did they worry about whether their intelligence measured up? And what could help them adopt and maintain a growth mindset during those times? We adapted procedures from user-centered design: $A / B$ tests (in which small variants on a message are tested against each other in multifactor randomized studies) and rapid prototyping (in which early-stage materials are shared with user groups who point out areas that could be improved). We learned, for example, that presenting students with both the fixed mindset and growth mindset in the short period of time we had was not as effective as just teaching a growth mindset. In Phase 3, we tested the product of this R\&D process- the "new" growthmindset intervention - against the "base" growth-mindset treatment, and we found that the revised intervention was in fact better at increasing challenge seeking (a marker of growthmindset behavior) at immediate posttest (Yeager, Romero, et al., 2016).

We then carried out a preregistered evaluation of the new intervention in a sample of 10 public high schools and found that it raised GPAs among lower achieving students in core classes (Yeager, Romero, et al., 2016). After more editing and rewriting, the "even newer" growth mindset intervention was finally ready for evaluation in a nationally representative sample of public high schools. The revised intervention showed positive effects at a national scale both in terms of grades for lower achieving students and challenge-seeking across both higher and lower achievers (Yeager, Hanselman, et al., 2018). We have also shared the intervention with economists who, after carrying out their own R\&D processes, replicated and extended the effects to students' achievement in Norway (Bettinger et al., 2018).

Although we now have a treatment that, in principle, could be scaled at very low cost to 9th graders across the United States, one take-home message from the R\&D process is how much interventions need to be tailored to particular populations. Therefore, it is not clear that even this revised treatment could be easily transported to other contexts, such as colleges or the workplace. Successful replication in these other settings may well require new rounds of R\&D (Yeager \& Walton, 2011). And, as we noted above, we plan to continue our $R \& D$ to further improve the current intervention in the future.

A third and final lesson from our experience bridging the two eras of mindset research is that direct-to-student treatments are only the beginning. That is, our initial interventions were useful for demonstrating causality and policy relevance. The student interventions were also a reasonable place to start because they grew out of careful prior work (both laboratory research and in-person interventions) that had been delivered directly to students. Moreover, individual treatments are often preferable in educational evaluation research because one can randomize at the person level and dramatically improve statistical power for main effects or for moderators. 
However, future work on how to promote and maintain growth mindset effects, we expect, will focus on the "mindset environment" and will foster collaborations with researchers from other disciplines that have historically studied the effects of social contexts, such as organizational science and sociology. That is, it is time to turn more seriously to an examination of the mindsets conveyed by or embodied in the environments that students (or adults) are in. What are the teacher (employer) practices in terms of types of work given, feedback for successes and struggles, opportunities for improvement, evaluation policies, and so on? We consider this next.

\section{Building Growth Mindset Cultures: Promise and Obstacles}

My colleagues and I (C. Dweck) have proposed that an even more effective and lasting approach might be to imbue an environment with instructional tasks and practices that foster a growth mindset. Only when this happens will we know the full potential of growth mindsets to affect motivation and learning. Contexts, or even whole organizations, can embody a mindset, and this is a potentially powerful force in shaping the beliefs, values, and behaviors of the people in those environments (Murphy \& Dweck, 2010).

The proposal to focus on the mindset environment may have a ring of truth, but it is much more easily said than done. At first, we naively thought it was straightforward to create a growth-mindset climate. Educators simply had to understand what a growth mindset was and think through how to communicate it to their students in words and actions. Our naiveté was fed by many communications from sophisticated educators who were implementing mindsets in original and compelling ways with noteworthy effects for their students.

However, over time, we learned that many educators who professed to have a growth mindset did not fully grasp what it was and were implementing practices that failed to communicate a growth mindset to their students. In some cases, we believe they were succeeding in doing just the opposite. We called this false growth mindset, a term coined by our Australian colleague Susan Mackie.

What forms did false growth mindset take? Many educators, it appeared, simply equated a growth mindset with effort-for example, praising effort, even when the student's effort was not effective. This could have the effect of leaving students feeling incompetent, as the educator simply accepts their lack of progress and tries to make them feel good about it. Moreover, focusing on effort alone (without bringing in the key role of good strategies and the essential role of mentorship, connections, and access to resources in success) could lead people to "blame the victim" if a person is not successful (see Levy, West, Ramirez, \& Karafantis, 2006). In a related vein, some educators told their students that they could do anything but did not provide them with strategies, guidance, or information about resources for the accomplishment of this promise. This could lead students to feel increasingly frustrated and inept if they fail to make progress toward their goals.

Yet other educators simply put up posters in the front of the room or gave a lecture on growth mindset and then returned to business as usual, expecting the students to do the rest. They might even reprimand those students who did not adopt the recommended mindset 
with its attendant practices, despite the fact that nothing else in the classroom changed to support a change in mindset. Some educators thought a growth mindset meant that all children were the same and that differences in current achievement levels could be ignored, often leaving advanced students unchallenged and bereft of meaningful learning. We learned a great deal from these practices and realized that educators needed far more guidance than we had provided. How, in fact, are growth-mindset cultures created in the classroom?

As a first step, new research by Mary Murphy and her colleagues has looked into college classrooms to understand which instructor practices promote different mindset climates or cultures. In a large and intensive study of college science, technology, engineering and mathematics (STEM) professors, they are finding that these professors' mindsets do in fact predict their classroom practices and the achievement of students in their classes, particularly the students from underserved or stigmatized groups, such as women and African American, Latinx, or first-generation students (Canning, Muenks, Green, \& Murphy, in press). In fact, they find significantly larger racial achievement gaps in STEM classes taught by teachers who endorse more of a fixed mindset (vs. a growth mindset).

With regard to teaching practices, Murphy and colleague are finding that STEM professors who are perceived by their students to endorse more of a growth mindset are more likely (a) to engage in process- focused teaching (e.g., monitoring student progress, adapting instruction as needed); (b) to communicate positive views of effort (e.g., telling students it is important to give their full effort even if they do not always get things right); and (c) to deliver process praise (e.g., praising students' problem-solving strategies, pointing out and complimenting students' progress and development; Muenks et al., 2018). Consistent findings are beginning to emerge from the National Study of Learning Mindsets, which included data from math teachers and their students in a national sample of 9th-grade math classes in the United States.

The research on the mindset environment is providing the basis for a rigorous and validated curriculum that can help teachers gain an accurate understanding of a growth mindset and develop teaching practices that embody it and communicate it to their students. Such a curriculum is now being developed and tested by Stephanie Fryberg and Mary Murphy in collaboration with educators from the Seattle Public Schools. When it is completed and fully evaluated, it will be made available at no cost to schools.

To summarize this section, current direct-to-student programs do not tell us about the full potential of growth-mindset concepts and practices to enhance motivation and learning. We will understand this more clearly when educators (and leaders of all kinds) create environments in which challenges are greeted with relish rather than dread, mistakes are learned from rather than punished, people collaborate to formulate effective learning strategies, and everyone's talents are deeply respected and vigorously developed.

\section{Bringing Mindset Interventions to the Social Domain}

Can mindsets about one's social attributes play a role in mental health, social coping, and well-being? About the same time that we (D. Yeager and colleagues) were learning how to 
take intelligence mindset interventions online, we were learning how to adapt the template to craft new interventions in the social domain. These studies have brought mindset theory to bear on other social problems.

My research built on the basic research on "personality" mindsets (Chiu et al., 1997; Erdley \& Dweck, 1993; Molden et al., 2006; Plaks, 2017) and took these mindsets into the world of high school victimization and aggression (Yeager, Trzesniewski, Tirri, Nokelainen, \& Dweck, 2011; see also Yeager \& Dweck, 2012). We found that some high school students had more of a fixed mindset about social qualities- the belief that being a good or bad person, a winner or a loser, a bully or a victim was a fixed trait. In line with this, they were more likely to view a peer's bullying behavior as a sign that the peer was fundamentally "bad" and, at the same time, a sign that they themselves were "not likable" or a "loser." These fixed trait attributions led to greater reports of shame and a greater desire for revenge. A short experiment (Yeager et al., 2011, Study 3) found that a growth-mindset manipulation reduced these tendencies among adolescents responding to a hypothetical bullying scenario.

Building on the example set by the J. M. Aronson et al. (2002) and Blackwell et al. (2007) growth-mind-set-of-intelligence workshops, Yeager, Trzesniewski, and Dweck (2013) asked whether an in-person workshop to change personality mindsets in an urban high school might lead to reductions in aggressive behavior (Yeager et al., 2013). In six $\sim 45$-min, faceto-face sessions with trained workshop leaders, students learned that people's socially relevant traits have the potential to change. The growth-mindset message was this: people's behaviors often come from thoughts and feelings, which live in the brain, and can be changed. They learned that change was not easy or certain, but that people had the potential for change, especially in adolescence. The intervention taught this message via scientific content about the brain and evidence of how changing people's thoughts and feelings can influence their aggression (e.g., Dodge et al., 2015).

One month after the program, we measured students' aggression with a behavioral paradigm. Students first had a brief experience of exclusion by peers in an online game, Cyberball (Williams, Yeager, Cheung, \& Choi, 2012), which was followed by an opportunity to retaliate. Specifically, they had to decide how much spicy hot sauce (an amount greater than zero) to allocate to a peer who excluded them (Lieberman, Solomon, Greenberg, \& McGregor, 1999), knowing full well that the peer disliked spicy foods. (Of course, students were thoroughly debriefed. They understood that no one was excluded and no one was required to eat hot sauce, and they enjoyed discussing the experience afterward.) Relative to two control conditions-a no-treatment control and a control group that was taught best-inclass coping skills- the growth-mindset-of-personality intervention substantially reduced the amount of hot sauce allocated to the peer, signaling less retaliatory aggression. The growth-mindset intervention also increased the number of prosocial notes students wrote to accompany the hot sauce, signaling a greater degree of empathy. These findings were confirmed by an analysis of teacher ratings of student conduct at the end of the school year (Yeager et al., 2013).

Newer research is taking the personality-mindset intervention into the domains of stress and depression, both of which can increase dramatically in adolescence (Miu \& Yeager, 2015; 
Schleider \& Weisz, 2016; Yeager, Lee, \& Jamieson, 2016). This research is showing that these interventions can improve coping and well-being over time and, in doing so, suggest that it can be a relief for adolescents to hear a compelling message that people have the potential for change, that the stressful social experiences they are having are not a reflection of who they are and who they have the potential to be, and therefore that these negative experiences are not inevitable in the future (see Yeager et al., 2014).

It is not just adolescents' problematic relationships that can be influenced by mindsets. In a program of research conducted in the Middle East, Halperin, Russell, Trzesniewski, Gross, and Dweck (2011) and Goldenberg et al. (2017) have examined the effects of teaching Israelis and Palestinians a growth mindset about groups, the belief that groups do not have a fixed, inherent nature (e.g., as evil or violent), but rather always have the potential for growth and change. In this research, the other group involved in the conflict in question was not mentioned so as not to imply that the researchers had an agenda and so as not to evoke reactance. In both short-term experiments (Halperin et al., 2011) and a longer term experiment (involving a 5-hr "leadership" workshop and a 6-month follow-up, Goldenberg et al., 2018), those in the growth-mindset groups, compared with the control group, showed more positive attitudes toward the other party, as well as greater willingness to entertain important concessions for the sake of peace. In addition, in the latter study the group differences were maintained over the 6-month period. Although this is just a beginning, these initial findings are promising and may provide insights for future conflict resolution efforts.

\section{Conclusion}

\section{Looking toward the future}

Together, we have presented a history of mindset research from its inception up to the present. Although in some ways the work is mature, in many ways it is still in its youth because there is so much more to learn.

As we have noted, we have much to learn about where mindset interventions do and do not work well. Toward that end, we are working closely with sociologists, economists, and statisticians to understand context effects more fully. And our colleagues are working to develop programs that will help create contexts in which growth mindsets, with their attendant challenge seeking and resilience, can more readily take root.

Can growth mindsets be woven into specific material to catalyze learning? We are extremely interested in how mindsets can be integrated into rigorous learning curricula to help students thrive in the face of challenges. Several expertly done integrations have worked well so far (Andersen \& Nielsen, 2016; Bryk, Gomez, Grunow, \& LeMahieu, 2015; O’Rourke, Haimovitz, Ballweber, Dweck, \& Popovic, 2014) and we expect that more will emerge in the future.

We are continuing to spell out the broader theoretical and practical implications of the mindset approach. On a theoretical level, one of us (C. Dweck) has recently proposed a unified theory of motivation, personality, and development that is organized around the 
development of beliefs and belief systems (Dweck, 2017). It shows how these beliefs can shape motivation and play a role in the formation of personality. Both of us have explored the question of why so many extensive, costly interventions that seem to work with children often seem to fail when given to adolescents-and have suggested how an analysis of mindset interventions and other brief psychological interventions can provide guidelines to help them succeed (Yeager, Dahl, \& Dweck, 2018).

\title{
Looking back
}

What have we learned? Above all, we have learned that this research is hard to do: It takes many years of hard work on the part of many dedicated people to build a research program and to take it out into the real world. We have also learned that era-bridging research - that is, research that successfully makes a transition from one era's methods and models to another's - is important for cumulative science. Finally, we have learned that there are few things in life as gratifying as studying human potential and growth and believing that perhaps you are doing your small part to promote it.

\section{Supplementary Material}

Refer to Web version on PubMed Central for supplementary material.

\section{Acknowledgments}

\author{
Funding
}

Writing of this article was supported in part by the William T. Grant Foundation and Eunice Kennedy Shriver National Institute of Child Health and Human Development Grants R01-HD084772 (to D. S. Yeager) and P2CHD042849 (to the Population Research Center at The University of Texas at Austin).

\section{References}

Andersen SC, \& Nielsen HS (2016). Reading intervention with a growth mindset approach improves children's skills. Proceedings of the National Academy of Sciences, USA, 113, 12111-12113. doi: 10.1073/pnas.1607946113

Aronson E (1999). The power of self-persuasion. American Psychologist, 54, 875-884. doi:10.1037/ h0088188

Aronson JM, Fried CB, \& Good C (2002). Reducing the effects of stereotype threat on African American college students by shaping theories of intelligence. Journal of Experimental Social Psychology, 38, 113-125. doi:10.1006/jesp.2001.1491

Bandura MM (1983). Children's conceptions of intelligence in relation to achievement goals and patterns of achievement-related cognitions, affect, and behavior (Doctoral dissertation). The Pennsylvania State University, University Park.

Bettinger EP, Ludvigsen S, Rege M, Solli IF, \& Yeager DS (2018). Increasing perseverance in math: Evidence from a field experiment in Norway. Journal of Economic Behavior \& Organization, 146, 1-15. doi: 10.1016/j.jebo.2017.11.032

Blackwell LS, Trzesniewski KH, \& Dweck CS (2007). Implicit theories of intelligence predict achievement across an adolescent transition: A longitudinal study and an intervention. Child Development, 78, 246-263. doi:10.1111/j.1467-8624.2007.00995.x [PubMed: 17328703]

Boulay B, Goodson B, Olsen R, McCormick R, Darrow C, Frye M,... Sarna M (2018). The Investing in Innovation Fund: Summary of 67 evaluations (NCEE No. 2018-4013). Washington, DC: National Center for Education Evaluation and Regional Assistance, Institute of Education Sciences, U.S. Department of Education. 
Broda M, Yun J, Schneider B, Yeager DS, Walton GM, \& Diemer M (2018). Reducing inequality in academic success for incoming college students: A randomized trial of growth mindset and belonging interventions. Journal of Research on Educational Effectiveness, 11, 317-338. doi: $10.1080 / 19345747.2018 .1429037$

Bryk AS, Gomez LM, Grunow A, \& LeMahieu PG (2015). Learning to improve: How America's schools can get better at getting better. Cambridge, MA: Harvard Education Press.

Canning EA, Muenks K, Green DJ, \& Murphy MC (in press). STEM faculty who believe ability is innate have larger racial achievement gaps and inspire less student motivation in their classes. Science Advances.

Carr PB, Dweck CS, \& Pauker K (2012). "Prejudiced" behavior without prejudice? Beliefs about the malleability of prejudice affect interracial interactions. Journal of Personality and Social Psychology, 103, 452-471. doi:10.1037/a0028849 [PubMed: 22708626]

Carroll JM, Muller C, Grodsky E, \& Warren JR (2017). Tracking health inequalities from high school to midlife. Social Forces, 96, 591-628. doi:10.1093/sf/sox065

Cheung ACK, \& Slavin RE (2016). How methodological features affect effect sizes in education. Educational Researcher, 45, 283-292. doi:10.3102/0013189X16656615

Chiu C, Hong Y, \& Dweck CS (1997). Lay dispositionism and implicit theories of personality. Journal of Personality and Social Psychology, 73, 19-30. doi: 10.1037/0022-3514.73.1.19 [PubMed: 9216077]

Cimpian A, Arce H-MC, Markman EM, \& Dweck CS (2007). Subtle linguistic cues affect children's motivation. Psychological Science, 18, 314-316. doi:10.1111/j.1467-9280.2007.01896.x [PubMed: 17470255]

Cohen J (1988). Statistical power analysis for the behavioral sciences (2nd ed.). Hillsdale, NJ: Erlbaum.

Diener CI, \& Dweck CS (1978). An analysis of learned helplessness: Continuous changes in performance, strategy, and achievement cognitions following failure. Journal of Personality and Social Psychology, 36, 451. doi:10.1037/0022-3514.36.5.451

Dodge KA, Bierman KL, Coie JD, Greenberg MT, Lochman JE, \& McMahon RJ,... Conduct Problems Prevention Research Group. (2015). Impact of early intervention on psychopathology, crime, and well-being at age 25. American Journal of Psychiatry, 172, 59-70. doi:10.1176/ appi.ajp.2014.13060786 [PubMed: 25219348]

Dweck CS (2006). Mindset: The new psychology of success. New York, NY: Random House.

Dweck CS (2017). From needs to goals and representations: Foundations for a unified theory of motivation, personality, and development. Psychological Review, 124, 689-719. doi:10.1037/ rev0000082 [PubMed: 28933872]

Dweck CS, Chiu C, \& Hong Y (1995). Implicit theories and their role in judgments and reactions: A world from two perspectives. Psychological Inquiry, 6, 267-285. doi:10.1207/ s15327965pli0604_1

Dweck CS, \& Leggett EL (1988). A social-cognitive approach to motivation and personality. Psychological Review, 95, 256-273. doi:10.1037/0033-295X.95.2.256

Dweck CS, \& Reppucci ND (1973). Learned helplessness and reinforcement responsibility in children. Journal of Personality and Social Psychology, 25, 109-116. doi:10.1037/h0034248

Dynarski SM (2017). For better learning in college lectures, lay down the laptop and pick up a pen. The Brookings Institution Retrieved from https://www.brookings.edu/research/for-better-learningin-college-lectures-lay-down-the-laptop-and-pick-up-a-pen/

Elliott ES, \& Dweck CS (1988). Goals: An approach to motivation and achievement. Journal of Personality and Social Psychology, 54, 5-12. doi:10.1037//0022-3514.54.1.5 [PubMed: 3346808]

Erdley CA, \& Dweck CS (1993). Children's implicit personality theories as predictors of their social judgments. Child Development, 64, 863-878. doi:10.2307/1131223 [PubMed: 8339700]

Goldenberg A, Cohen-Chen S, Goyer JP, Dweck CS, Gross JJ, \& Halperin E (2018). Testing the impact and durability of a group malleability intervention in the context of the Israeli-Palestinian conflict. Proceedings of the National Academy of Sciences, USA, 115, 696-701. doi:10.1073/ pnas. 1706800115 
Goldenberg A, Endevelt K, Ran S, Dweck CS, Gross JJ, \& Halperin E (2017). Making intergroup contact more fruitful: Enhancing cooperation between Palestinian and Jewish-Israeli adolescents by fostering beliefs about group malleability. Social Psychological \& Personality Science, 8, 3-10. doi:10.1177/1948550616672851

Good C, Aronson J, \& Inzlicht M (2003). Improving adolescents' standardized test performance: An intervention to reduce the effects of stereotype threat. Journal of Applied Developmental Psychology, 24, 645-662. doi: 10.1016/j.appdev.2003.09.002

Grant H, \& Dweck CS (2003). Clarifying achievement goals and their impact. Journal of Personality and Social Psychology, 85, 541-553. doi:10.1037/0022-3514.85.3.541 [PubMed: 14498789]

Gunderson EA, Gripshover SJ, Romero C, Dweck CS, Goldin-Meadow S, \& Levine SC (2013). Parent praise to 1- to 3-year-olds predicts children's motivational frameworks 5 years later. Child Development, 84, 1526-1541. doi:10.1111/cdev.12064 [PubMed: 23397904]

Guthrie ER (1935). The psychology of learning. New York, NY: Harper \& Brothers.

Haimovitz K, \& Dweck CS (2016). Parents' views of failure predict children's fixed and growth intelligence mind-sets. Psychological Science, 27, 859-869. doi:10.1177/0956797616639727 [PubMed: 27113733]

Haimovitz K, \& Dweck CS (2017). The origins of children's growth and fixed mindsets: New research and a new proposal. Child Development, 88, 1849-1859. doi:10.1111/cdev.12955 [PubMed: 28905371]

Halperin E, Russell AG, Trzesniewski KH, Gross JJ, \& Dweck CS (2011). Promoting the Middle East peace process by changing beliefs about group malleability. Science, 333, 1767-1769. doi: 10.1126/science.1202925 [PubMed: 21868627]

Hill CJ, Bloom HS, Black AR, \& Lipsey MW (2008). Empirical benchmarks for interpreting effect sizes in research. Child Development Perspectives, 2, 172-177. doi:10.1111/j. 1750-8606.2008.00061.x

Hong Y, Chiu C, Dweck CS, Lin DM-S, \& Wan W (1999). Implicit theories, attributions, and coping: A meaning system approach. Journal of Personality and Social Psychology, 77, 588-599. doi: 10.1037/0022-3514.77.3.588

Kamins ML, \& Dweck CS (1999). Person versus process praise and criticism: Implications for contingent self-worth and coping. Developmental Psychology, 35, 835-847. doi: 10.1037/0012-1649.35.3.835 [PubMed: 10380873]

Leggett EL (1986). Individual differences in effort/ability inference rules and goals: Implications for causal judgments. Dissertation Abstracts International, 47(6-B), 2662.

Levy SR, \& Dweck CS (1999). The impact of children's static versus dynamic conceptions of people on stereotype formation. Child Development, 70, 1163-1180. doi:10.1111/1467-8624.00085

Levy SR, Plaks JE, Hong Y, Chiu C, \& Dweck CS (2001). Static versus dynamic theories and the perception of groups: Different routes to different destinations. Personality and Social Psychology Review, 5, 156-168. doi:10.1207/S15327957PSPR0502_6

Levy SR, Stroessner SJ, \& Dweck CS (1998). Stereotype formation and endorsement: The role of implicit theories. Journal of Personality and Social Psychology, 74, 1421-1436. doi: 10.1037/0022-3514.74.6.1421

Levy SR, West TL, Ramirez L, \& Karafantis DM (2006). The protestant work ethic: A lay theory with dual intergroup implications. Group Processes \& Intergroup Relations, 9, 95-115. doi: $10.1177 / 1368430206059874$

Lieberman JD, Solomon S, Greenberg J, \& McGregor HA (1999). A hot new way to measure aggression: Hot sauce allocation. Aggressive Behavior, 25, 331348. doi:10.1002/ (SICI) 1098-2337(1999)25:5<331::AID-AB2>3.0.CO;2-1

Mangels JA, Butterfield B, Lamb J, Good C, \& Dweck CS (2006). Why do beliefs about intelligence influence learning success? A social cognitive neuroscience model. Social Cognitive and Affective Neuroscience, 1, 75-86. doi:10.1093/scan/ns1013 [PubMed: 17392928]

McConnell AR (2001). Implicit theories: Consequences for social judgments of individuals. Journal of Experimental Social Psychology, 37, 215-227. doi:10.1006/jesp.2000.1445 
Miele DB, \& Molden DC (2010). Naive theories of intelligence and the role of processing fluency in perceived comprehension. Journal of Experimental Psychology: General, 139, 535-557. doi: 10.1037/a0019745 [PubMed: 20677898]

Miele DB, Son LK, \& Metcalfe J (2013). Children's naive theories of intelligence influence their metacognitive judgments. Child Development, 84, 1879-1886. doi:10.1111/cdev.12101 [PubMed: 23574195]

Miu AS, \& Yeager DS (2015). Preventing symptoms of depression by teaching adolescents that people can change: Effects of a brief incremental theory of personality intervention at 9-month follow-up. Clinical Psychological Science, 3, 726-743. doi:10.1177/2167702614548317

Molden DC, \& Dweck CS (2006). Finding "meaning” in psychology: A lay theories approach to selfregulation, social perception, and social development. American Psychologist, 61, 192-203. doi: 10.1037/0003-066X.61.3.192 [PubMed: 16594836]

Molden DC, Plaks JE, \& Dweck CS (2006). "Meaningful” social inferences: Effects of implicit theories on inferential processes. Journal of Experimental Social Psychology, 42, 738-752. doi: 10.1016/j.jesp.2005.11.005

Moser JS, Schroder HS, Heeter C, Moran TP, \& Lee Y-H (2011). Mind your errors: Evidence for a neural mechanism linking growth mind-set to adaptive posterror adjustments. Psychological Science, 22, 1484-1489. doi:10.1177/0956797611419520 [PubMed: 22042726]

Mueller CM, \& Dweck CS (1998). Praise for intelligence can undermine children's motivation and performance. Journal of Personality and Social Psychology, 75, 33-52. doi: 10.1037/0022-3514.75.1.33 [PubMed: 9686450]

Muenks K, Canning EA, Green DJ, Zirkel S, Garcia JA, \& Murphy MC (2018). Does my professor think my ability can change? Students' perceptions of their STEM professors' mindset predict inclass psychological experiences. Unpublished manuscript, University of Texas at Austin.

Murphy MC, \& Dweck CS (2010). A culture of genius: How an organization's lay theory shapes people's cognition, affect, and behavior. Personality and Social Psychology Bulletin, 36, 283-296. doi:10.1177/0146167209347380 [PubMed: 19826076]

Nicholls JG (1984). Achievement motivation: Conceptions of ability, subjective experience, task choice, and performance. Psychological Review, 91, 328-346. doi: 10.1037/0033-295X.91.3.328

Nussbaum AD, \& Dweck CS (2008). Defensiveness versus remediation: Self-theories and modes of self-esteem maintenance. Personality and Social Psychology Bulletin, 34, 599-612. doi: 10.1177/0146167207312960 [PubMed: 18276895]

Nye B, Hedges LV, \& Konstantopoulos S(2000). The effects of small classes on academic achievement: The results of the Tennessee class size experiment. American Educational Research Journal, 37, 123-151. doi:10.3102/00028312037001123

O’Rourke E, Haimovitz K, Ballweber C, Dweck CS, \& Popovic Z (2014). Brain Points: A growth mindset incentive structure boosts persistence in an educational game In CHI 2014: Proceedings of the SIGCHI conference on human factors in computing systems (pp. 3339-3348). New York, NY: ACM. doi:10.1145/2556288.2557157

Owens A, Reardon SF, \& Jencks C (2016). Income segregation between schools and school districts. American Educational Research Journal, 53, 1159-1197. doi:10.3102/0002831216652722

Paunesku D, Walton GM, Romero C, Smith EN, Yeager DS, \& Dweck CS (2015). Mind-set interventions are a scalable treatment for academic underachievement. Psychological Science, 26, 784-793. doi: 10.1177/0956797615571017 [PubMed: 25862544]

Pico della Mirandola G (2012). On the dignity of man: A new translation and commentary (Borghesi F, Papio M, \& Riva M, Eds.). New York, NY: Cambridge University Press. doi: 10.1017/ CBO9781139059565 (Original work published 1486)

Plaks JE (2017). Implicit theories: Assumptions that shape social and moral cognition In Olson JM(Ed.), Advances in experimental social psychology (Vol. 56, pp. 259-310). New York, NY: Academic Press. doi10.1016/bs.aesp.2017.02.003

Plaks JE, Stroessner SJ, Dweck CS, \& Sherman JW (2001). Person theories and attention allocation: Preferences for stereotypic versus counterstereotypic information. Journal of Personality and Social Psychology, 80, 876-893. doi:10.1037/0022-3514.80.6.876 [PubMed: 11414372] 
Pomerantz EM, \& Kempner SG (2013). Mothers' daily person and process praise: Implications for children's theory of intelligence and motivation. Developmental Psychology, 49, 2040-2046. doi: 10.1037/a0031840 [PubMed: 23398552]

Robins RW, \& Pals JL (2002). Implicit self-theories in the academic domain: Implications for goal orientation, attributions, affect, and self-esteem change. Self and Identity, 1, 313-336. doi: $10.1080 / 15298860290106805$

Sauce B, \& Matzel LD (2018). The paradox of intelligence: Heritability and malleability coexist in hidden gene-environment interplay. Psychological Bulletin, 144, 26-47. doi:10.1037/bul0000131 [PubMed: 29083200]

Schleider JL, \& Weisz JR (2016). Reducing risk for anxiety and depression in adolescents: Effects of a single-session intervention teaching that personality can change. Behaviour Research and Therapy, 87, 170-181. doi:10.1016/j.brat.2016.09.011 [PubMed: 27697671]

Seligman ME, \& Maier SF (1967). Failure to escape traumatic shock. Journal of Experimental Psychology, 74, 1-9. doi:10.1037/h0024514 [PubMed: 6032570]

Somers M-A, Corrin W, Sepanik S, Salinger T, Levin J, \& Zmack C (2010). The enhanced reading opportunities study final report: The impact of supplemental literacy courses for struggling ninthgrade readers (NCEE No. 2010-4022). Washington, DC: Institute of Education Sciences Retrieved from https://ies.ed.gov/ncee/pubs/20104021/pdf/20104022.pdf

Walton GM (2014). The new science of wise psychological interventions. Current Directions in Psychological Science, 23, 73-82. doi:10.1177/0963721413512856

Weiner B, \& Kukla A (1970). An attributional analysis of achievement motivation. Journal of Personality and Social Psychology, 15, 1-20. doi:10.1037/h0029211

Weiss MJ, Bloom HS, Verbitsky-Savitz N, Gupta H, Vigil AE, \& Cullinan DN (2017). How much do the effects of education and training programs vary across sites? Evidence from past multisite randomized trials. Journal of Research on Educational Effectiveness, 10, 843-876. doi: 10.1080/19345747.2017.1300719

West MR, Buckley K, Krachman SB, \& Bookman N (2018). Development and implementation of student social-emotional surveys in the CORE Districts. Journal of Applied Developmental Psychology, 55, 119-129. doi:10.1016/j.appdev.2017.06.001

Williams KD, Yeager DS, Cheung C, \& Choi W (2012). Cyberball (Version 4.0) [Computer software]. Available from https://cyberball.wikispaces.com

Wilson TD (2011). Redirect: The surprising new science of psychological change. London, England: Penguin UK.

Yeager DS, Dahl RE, \& Dweck CS (2018). Why interventions to influence adolescent behavior often fail but could succeed. Perspectives on Psychological Science, 13, 101-122. doi: 10.1177/1745691617722620 [PubMed: 29232535]

Yeager DS, \& Dweck CS (2012). Mindsets that promote resilience: When students believe that personal characteristics can be developed. Educational Psychologist, 47, 302-314. doi: 10.1080/00461520.2012.722805

Yeager DS, Hanselman P, Walton GM, Crosnoe R, Muller CL, Tipton E,... Dweck CS (2018). Where does a scalable growth-mindset intervention improve adolescents' educational trajectories? Unpublished manuscript, University of Texas at Austin.

Yeager DS, Johnson R, Spitzer BJ, Trzesniewski KH, Powers J, \& Dweck CS (2014). The far-reaching effects of believing people can change: Implicit theories of personality shape stress, health, and achievement during adolescence. Journal of Personality and Social Psychology, 106, 867-884. doi: 10.1037/a0036335 [PubMed: 24841093]

Yeager DS, Lee HY, \& Jamieson JP (2016). How to improve adolescent stress responses: Insights from integrating implicit theories of personality and biopsychosocial models. Psychological Science, 27, 1078-1091. doi:10.1177/0956797616649604 [PubMed: 27324267]

Yeager DS, Romero C, Paunesku D, Hulleman CS, Schneider B, Hinojosa C,... Dweck CS (2016). Using design thinking to improve psychological interventions: The case of the growth mindset during the transition to high school. Journal of Educational Psychology, 108, 374-391. doi: 10.1037/edu0000098 [PubMed: 27524832] 
Yeager DS, Trzesniewski KH, \& Dweck CS (2013). An implicit theories of personality intervention reduces adolescent aggression in response to victimization and exclusion. Child Development, 84, 970-988. doi:10.1111/cdev.12003 [PubMed: 23106262]

Yeager DS, Trzesniewski KH, Tirri K, Nokelainen P, \& Dweck CS (2011). Adolescents' implicit theories predict desire for vengeance after peer conflicts: Correlational and experimental evidence. Developmental Psychology, 47, 1090-1107. doi:10.1037/a0023769 [PubMed: 21604865]

Yeager DS, \& Walton GM (2011). Social-psychological interventions in education: They're not magic. Review of Educational Research, 81, 267-301. doi:10.3102/0034654311405999

Yeager DS, Walton GM, Brady ST, Akcinar EN, Paunesku D, Keane L,... Dweck, C. S. (2016). Teaching a lay theory before college narrows achievement gaps at scale. Proceedings of the National Academy of Sciences, USA, 113, E3341-E3348. doi:10.1073/pnas.1524360113

Zhao L, Heyman GD, Chen L, \& Lee K (2017). Praising young children for being smart promotes cheating. Psychological Science, 28, 1868-1870. doi:10.1177/0956797617721529 [PubMed: 28898167] 


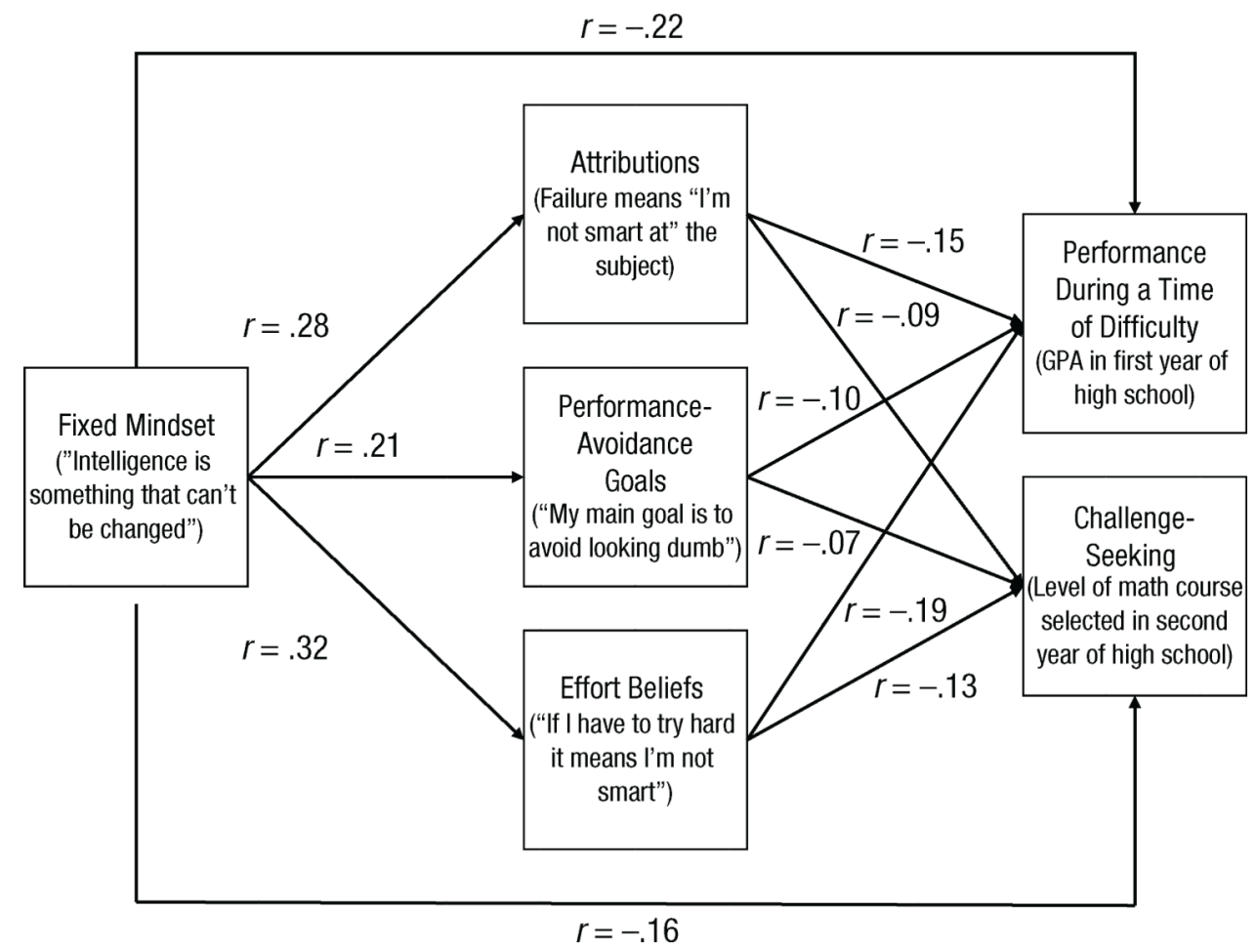

Fig. 1.

Predictions of the mindset-related meaning system for challenge seeking and performance and evidence for the predictions from a nationally representative sample of U.S. public high school students. Paths are zero-order correlations, not paths estimated simultaneously in a structural equation model. These paths are meant to illustrate the unadjusted strength of association and the conceptual framework and do not represent estimates of causal effects. All correlations are significant at $p<.001$. Data come from the National Study of Learning Mindsets (Yeager, Hanselman, et al., 2018), which involved a representative sample of 9thgrade students in U.S. public schools surveyed in the fall of 2015 and followed until 2016. Max $N=14,530$. Exact items and sample sizes are reported in the Supplemental Material available online. The data were collected using systems and processes developed by the Project for Education Research That Scales (PERTS; http://www.perts.net, PI: David Paunesku). 


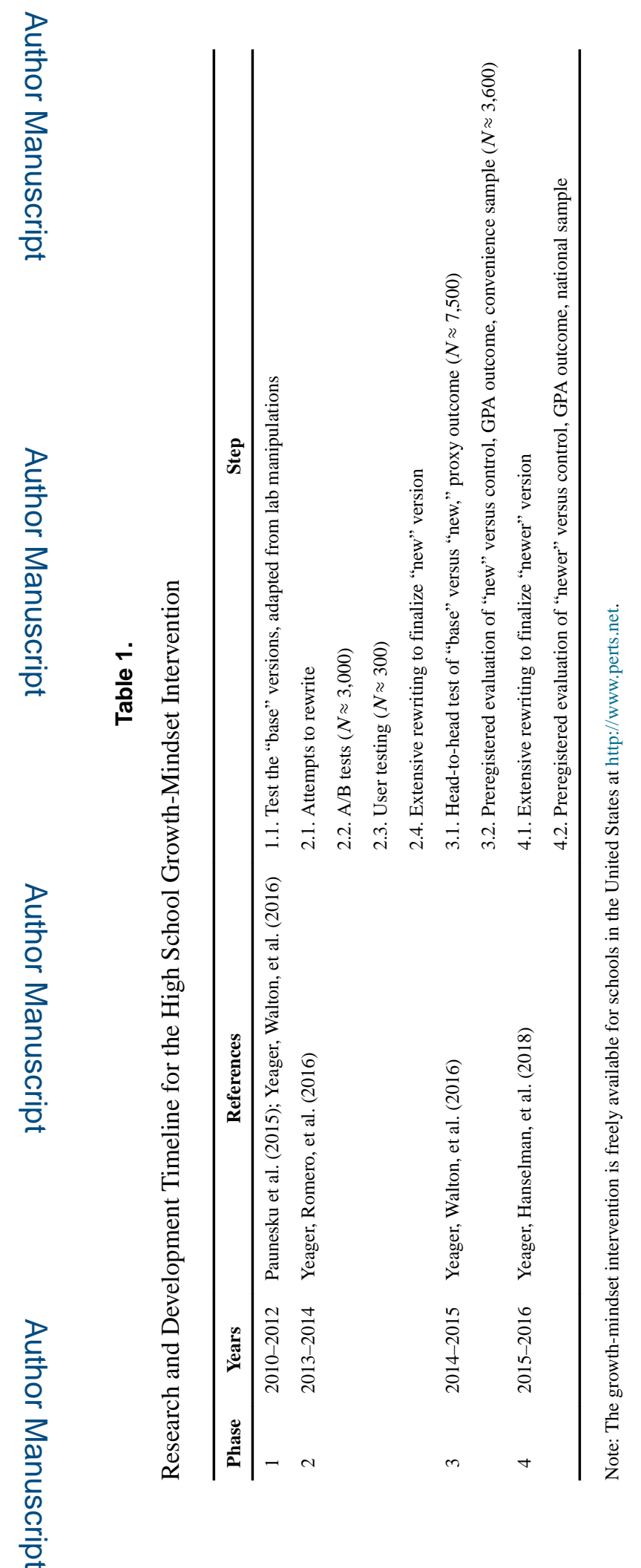

Perspect Psychol Sci. Author manuscript; available in PMC 2020 May 01. 